\section{Beyond the Book}

\section{Encouraging Emerging Readers}

\author{
MARYBETH KOZIKOWSKI AND KERRI WILLLAMS
}

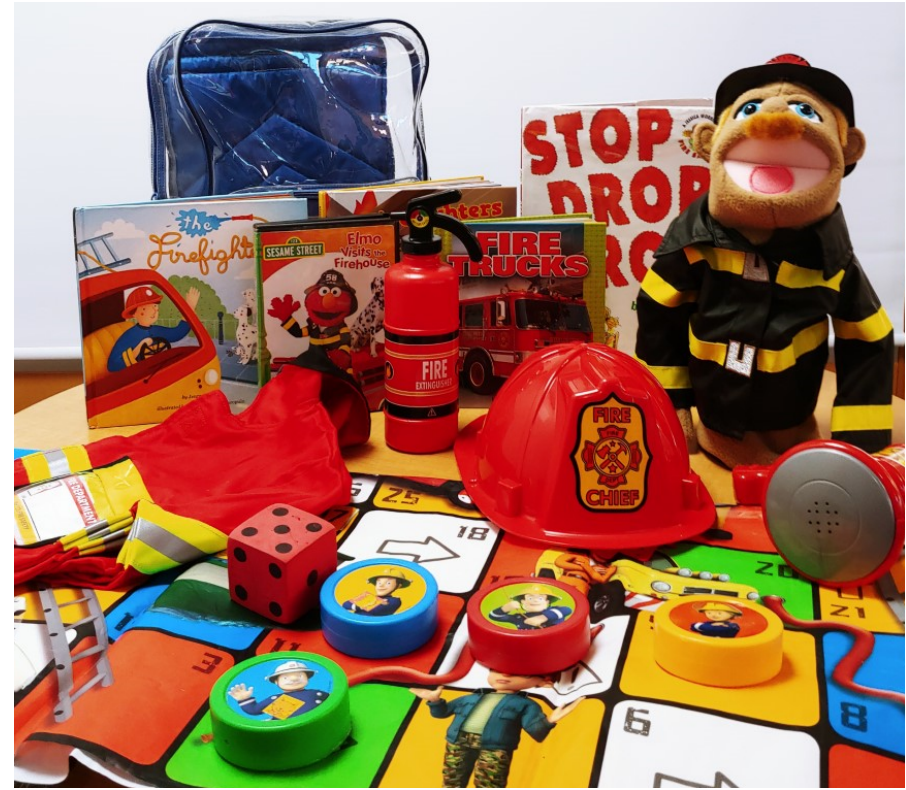

One of the very popular theme kits at Center Moriches Free Public Library in New York. Photo courtesy of Kerri Williams Forrester.

Fostering Readers' pilot project survey indicated 44 percent of public library sessions attracted families new to the library. Participating afterschool providers reported that about 70 percent of participating children chose books for their quiet time following Fostering Readers activities-substantially more than expected based on children's prior behavior. One afterschool provider commented, "We had never seen children sit and read for ninety minutes or more during quiet time before."

Grade Level Reading Project: Denver, CO

In 2015, the Denver School District and Denver Public Library (DPL) partnered to create the Grade Level Reading Project. ${ }^{1}$ Its goal was to achieve citywide reading proficiency for students in grades $\mathrm{K}-3$. In response to the school district's articulated need for DPL to focus on the joy of reading and reading motivation for children and families, the library's Grade Level Reading Project Team created a series of action steps to

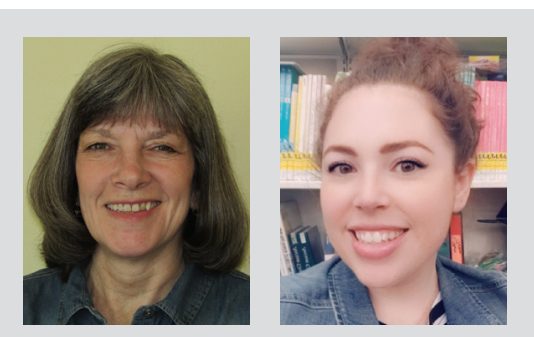

Marybeth Kozikowski is a Librarian II at Sachem Public Library, Holbrook, NY. She has served on multiple ALSC Committees, reviews for School Library Journal and is currently Vice President of the Children's Librarians Association of Suffolk County, NY. Kerri Williams is a Librarian I at the Center Moriches Free Public Library in NY and also reviews for School Library Journal. 
meet that need. Project Team member and children's librarian Amy Seto Forrester says the team began by developing five grade-level reading skills. ${ }^{2}$ While similar to ALA's Every Child Ready to Read (ECRR) @ your library (www.everychild readytoread.org) practices, DPL's five skills (background knowledge, comprehension, decoding, fluency, and reading motivation) support children already reading. These skills provide the framework to support and unify the library's literacy-based programs, readers' advisory, and outreach. DPL's action steps include creating Welcome to Reading kits, which introduce caregivers to excellent, engaging, and diverse books that support new readers. Each kit contains five books, one activity, and one tip sheet in a zippered clear plastic tote, making it quick and easy to check out.

DPL patrons may also request a personalized reading list to build motivation. Seto Forrester adds that staff has created early and transitional book subject headings in the online/ local catalog to make it easier for patrons and staff to find books for developing readers.

\section{Team Up to Read: Brooklyn, NY}

An interactive public library program series designed for children ages five to nine and their caregivers, Team Up to Read (www.bklynlibrary.org/event-series/team-up-to-read) employs caregiver tips and fun activities to encourage a lifelong love of reading. Created in 2018 by Kimberly Grad, coordinator of school-age services at Brooklyn Public Library, and funded by a grant from the Altman Foundation, Team Up to Read began as a weekend program led by freelance teachers and education students; each of the six sessions includes a read-aloud component and an activity. The curriculum's strategies, written by Mollie Welsh Kruger of Bank Street College, focus on six themes:

1. Being curious and stopping to ask questions while reading

\section{Creating an artistic response to a story}

3. Knowing the parts of the story

\section{Making connections to stories}

5. Strengthening fluency by retelling a story with puppets

6. Exploring nonfiction and poetry.

The strong emotional character experience in Gaia Cornwall's Jabari Jumps (Candlewick, 2017) was used in Team Up to Read to help young readers connect to a story. Draw! by Raul Colon (Simon \& Schuster, 2014) was chosen to encourage children's curiosity, to ask questions while reading, and think about who they are as readers. After attending Team Up to Read, parents reported that their children showed huge improvements in their reading skills and that their children enjoyed reading more than ever. ${ }^{3}$

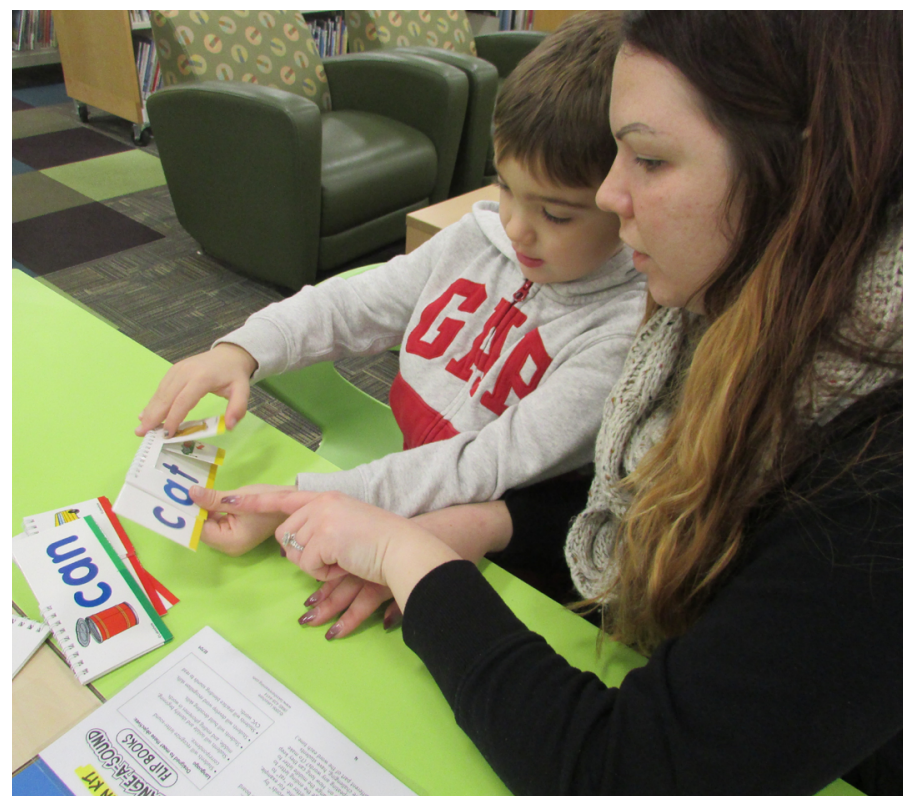

A caregiver and child enjoy sight word cards. Photo courtesy of Marybeth Kozikowski, Sachem Public Library.

\section{Get Real-ia}

A challenging part of serving our emerging readers is engaging them. Learning to read is hard, and sometimes books don't quite capture a child's heart or interest. That's where realia comes in, and many public libraries have come up with inventive ways to reach this underserved population. Most of these items include circulating kits and nontraditional items that can be used in or out of the library.

A little ingenuity and a lot of creativity transforms simple hexagonal porcelain tiles (sold by the sheet at home improvement stores) into an interactive learning game. Decorated with paint or rights-free internet images, sets include story tiles with images from well-known stories like The Three Little Pigs. The tiles encourage caregivers and children to retell or create their own stories, helping with story structure and building narratives. A color-themed set with accompanying cards encourages sorting images simply by color or naming objects and grouping them into categories, such as living/nonliving or clothing/food. Rhonda Cunha, early literacy children's librarian with Stevens Memorial Library (North Andover, MA), adds, "I am writing a guide for caregivers on how to use the story tiles with a child and plan to create additional sets with images of rhyming objects to build phonemic awareness."

Jennifer Wharton of the Matheson Memorial Library (Elkhorn, WI) creates an early literacy calendar for patrons. Each day of the month has an early literacy challenge focused on the ECRR skills of reading, writing, and talking-all centered around a word of the week. One word was "surprise," which included challenges such as "play hide and seek" and reading 
a recommended book, culminating in an activity to make a surprise gift for a friend or neighbor. This calendar is an easy way for families to practice their literacy skills every day, along with some general tips for parents. Wharton shares her early literacy calendar and a STEM calendar with other libraries, so that they may customize it.

\section{Circulating Kits}

Many libraries also circulate items so patrons can practice early literacy at home. As do many libraries, the Matheson Memorial Library circulates Early Literacy Kits that contain emerging reader books, CDs, toys, extension activities, and games centering on a theme.

Classroom-quality educational materials and tips for their use composes Sachem Public Library's (Holbrook, NY) indemand Learn to Read Kits. Each kit includes a talking sight word board, sight word puzzles, and spiral-bound cards that stress simple sentences or the beginning, middle, and end sounds of words. Sachem purchased materials from Lakeshore Learning Products (www.lakeshorelearning.com), selecting items with limited parts to make kits easier to maintain and streamline the return process. The most significant

\section{References}

1. "Resources for Developing Readers," Denver Public Library, https://kids.denverlibrary.org/activities/k-3 /resources-developing-readers.

2. “The Five Grade Level Reading Skills," Denver Public Library, https://docs.google.com/document/d/1o-5AD K0v8ihKcOG043NWz52rNRUhTvmoGcU-xFBdw4k/edit. items in the kits are teacher guides, which explain the skills each item helps develop.

At the Center Moriches (NY) Free Public Library, themed backpack kits are also circulated to young patrons. The most popular are the Sight Words kits, which are constantly checked out to parents of kindergarteners, our prime emerging reader target. These kits are very popular because they provide an easy way to practice with children at home, but what appeals to the kids? It could definitely be because of the fun early reader books, but let's be real-it's probably the puppets.

\section{Libraries Have a Role}

At a storytime in a community park a few years ago, a patron recognized and warmly welcomed our staff. With genuine emotion in her voice, our patron turned to her friends and said, “These ladies taught my son to read!" Well, while not exactly the case, her appreciation reinforces the important role librarians have to play in supporting emerging readers and their caregivers. Whether it's as a part of a citywide initiative or flying solo with a program or product our patrons love, we as librarians can help make achieving this milestone easier, creating a new generation of lifelong readers. \&

3. Kimberly Grad, "Team Up to Read Is Building Stronger Readers,” ALSC Blog, April 16, 2019, www.alsc.ala.org /blog/2019/04/team-up-to-read-is-building-stronger -readers-at-brooklyn-public-library. 